\title{
А.П. Царева
}

\section{"СВОБОАА ПОЛУЧИТЬ РАЗВОА НЕ ПРИВО-}

АИТ К СЧАСТЬЮ И АОБРОАЕТЕЛИ":

\section{ОТНОШЕНИЕ К РАЗВОАУ ПО АКТУ ПАРЛАМЕНТА В АНГАИИ XVIII ВEКА}

КАЮчевЫЕ СловА: развоА, брак, Англия, XVIII век, парламент.

АннотАция: Англия в XVIII веке отличалась от Аругих протестантских стран отсутствием широкого Аоступа к разводу, по большей части супруги оформляли разАельное проживание, расходились полуофициально или просто сбегали от своей второй половины. Развод по акту парламента с возможностью вступления в повторный брак не был широко востребован. ОАним из факторов, способствовавших этому, было его ассоциирование с ущербом репутации и морали. В статье проанализированы причины подобного отношения современников, включавшие распространение информации о мичной жизни; то, что единственным основанием Аля подобного типа развода являлась супружеская измена; опасение, что легкий Аоступ к процедуре подорвет общественную мораль. При этом в действительности урон репутации бывших супругов не всегда был непоправимым, а влияние разводов на общество в целом преувеличивалось, так как стоимость и Алительность процесса существенно ограничивали их доступность.

Известный исследователь семейной жизни в Англии в Новое время Лоренс Стоун называл общество этого периода «не расходящимся и не разводящимся» ${ }^{1}$, поскольку в Англии, в отличие от других протестантских стран, разорвать брачные отношения с правом повторно жениться или выйти замуж было весьма сложно, а имевшийся механизм оформле-

1 Stone. 1995: 2.

Александра Петровна Царева, к.и.н., преподаватель НИУ ВШЭ, alext86@bk.ru DOI: 10.32608/2307-8383-2021-29-023-042 
ния развода не получил широкого распространения. В своем фундаментальном исследовании по расторжению брака в этот период Стоун затрагивает законодательные, судебные, социальные, имущественные, моральные аспекты развода, основное внимание уделяя вопросам изменений в законодательстве и отношения судебных инстанций к делам о расторжении брака². В литературе рассматривали разводы через призму смены юрисдикции судебных инстанций ${ }^{3}$, в контексте моральных устоев высшего света ${ }^{4}$, социального состава участников ${ }^{5}$, их имущественного положения 6 , влияния гендерного фактора7. В данной статье мы рассмотрим факторы, способствовавшие негативному отношению англичан к процедуре парламентского развода и ее восприятию как наносящую ущерб репутации и морали. Л. Стоун частично затрагивает данный вопрос, когда пишет, что разведенные женщины сталкивались с одиночеством и социальным остракизмом; по его мнению, нельзя сделать однозначный вывод о том, смягчало ли ситуацию вступление в брак после развода ${ }^{8}$. В данной статье на примере леди Дианы Болингброк (впоследствии Боклерк) мы покажем, что последствия расторжения брака для социального статуса не всегда были необратимо негативными.

Английский юрист общего права Уильям Блэкстон отмечал существование нескольких видов развода, первые два

2 См.: Stone. 1995. Он также рассматривает конкретные примеры в сборнике, посвященном отдельным случаям расторжения брака: Stone. 1993.

3 Woodhouse. 1959.

4 Andrew. 1997.

5 James. 2012

6 Staves. 1990.

7 Rendall. 1985.

Stone. 1995: 340, 342. 


\section{Царева А.П. «Свобода получить развод...»}

из которых существовали в Англии еще до Реформации и восходят к католической традиции. Развод a vinculo matrimonii, имел место в том случае, если причина для него существовала еще до свадьбы (например, один из супругов оказывался душевнобольным или уже состоял в браке). В данной ситуации брак считался недействительным с самого начала, а дети таких супругов объявлялись незаконнорожденными. Второй вид развода, a mensa et thoro, предполагал разделение постели и крова (separation from bed and board) мужа и жены, то есть их раздельное проживание 9 . При этом супруги формально не были разведены, то есть не могли законно вступить в новый брак. При разделении постели и крова муж был обязан назначить жене фиксированное содержание, в случае невыплаты которого принимал на себя ответственность за ее долги ${ }^{10}$. В словаре английского языка, выпущенном в 1756 году, в качестве синонима к разводу (divorce) как раз выступает разделение (separation) ${ }^{11}$, что может вводить современного читателя в заблуждение, поскольку в юридической практике изучаемого периода использовался только первый термин, а второй официально был введен в оборот после принятия в 1857 году акта о браке (Matrimonial Causes Act) ${ }^{12}$, закрепившего законную процедуру развода. Уильям Блэкстон упоминает еще одну возможность получить полный развод a vinculo matrimonii. Для этого нужно было доказать факт супружеской измены и получить частный акт парламента о разводе ${ }^{13}$. Данная процедура поз-

9 Blackstone. 1768: 440-441.

10 Staves. 1990: 186.

11 Dictionary of the English language. 1756: n.p.

12 Stone. 1995: 47.

13 Blackstone. 1768: 441. 
воляла обеим сторонам на законных основаниях повторно выйти замуж или жениться.

Упомянутые выше официальные способы расторжения брака требовали значительных судебных издержек и были доступны не всем. Л. Стоун отмечает, что для необеспеченных слоев населения обычным делом было оставление супруга или супруги (desertion) без каких-либо юридических формальностей, в некоторых случаях законный статус в глазах окружающих пытались получить путем ритуальной продажи жены (wife-sale) на ярмарке за символическую плату, что, впрочем, не влияло на отношение суда к таким «разводам» как к не имеющим юридической силы. На практике многие представители низших классов считали себя свободными от обязательств, проведя описанные выше процедуры, и вступали во второй брак, что, однако, могло привести к обвинению в двоеженстве или двоемужестве, а первый супруг мог неожиданно заявить свои права на имущество или совместное проживание ${ }^{14}$.

Среди зажиточных супругов множество желающих расстаться также предпочитали не доводить дело до суда. Муж и жена могли полуофициально разойтись после заключения соглашения о расставании (separation deed), составленного с привлечением юристов, в которое обычно включался пункт с обязательством супругов не предъявлять претензии в судебном порядке, что имело целью дать возможности для совместного проживания, если не брака, с третьим лицом. Суды, впрочем, не признавали законность расторжения брака по соглашению15.

14 Stone. 1995: 142-144. Тезис о широком распространении двоеженства как формы повторного брака был подвергнут сомнению в литературе, например: Turner. 2005: 18.

15 Stone. 1995: 153. 


\section{Царева А.П. «Свобода получить развод...»}

Можно предположить, что малообеспеченных англичан останавливали высокие издержки в ходе судебного процесса. Тем не менее лица, не обладавшие значительным состоянием, могли обратиться в парламент in forma pauperis и признавать свое состояние составляющим менее 5 фунтов ${ }^{16}$, как, например, Уильям Чиппендэлл, носивший титул джентльмена и при этом работавший клерком у юриста ${ }^{17}$. При этом у исследователей нет серьезных оснований считать, что успех билля зависел от статуса подавшего его лица18. Таким образом, процедура парламентского развода была доступна как состоятельным людям (в большинстве случаев), так и тем, кто готов был формально признать себя бедняком.

Почему же люди не пользовались возможностью получить развод по акту парламента и законно вступить в повторный брак? Л. Стоун выделяет несколько мотивов: устойчивость семьи как экономической и социальной ячейки, патриархальная идеология, экономически подчиненное состояние жены и возможность потерять опеку над детьми, боязнь публичного обсуждения ${ }^{19}$. Пример традиционного взгляда на бракоразводный процесс можно найти в знаменитом «Новогоднем подарке для леди, или Совете дочери» (1688) маркиза Галифакса, который пишет:

...Аело о разводе ВыгляАит так непристойно, что мишь немногие соглашаются получить свободу ценой утраты собственной скромности ${ }^{20}$.

16 Woodhouse. 1959: 261.

17 James. 2012: 173.

18 James. 2012: 189.

19 Stone. 1993: 13-14.

20 Галифакс. 2001: 191. 
Наставление обращено к дочери, которой ясно дают понять, что основная вина за развод ложится на плечи женщины, чью репутацию губит подобный шаг. Именно поэтому маркиз дает советы, как переносить жизнь с любым мужем: пьяницей, игроком, дураком и так далее. Таким образом, одно из существенных возражений против разводов было связано с возможным ущербом репутации, особенно репутации женщины.

Для мужчин развод также не был предпочтительным вариантом. Знаменитый лексикограф Сэмюэл Джонсон советует знакомому:

В неподхояящий или несчастливый брак вступают кажАый Аень множество ^юдей, и вам следует стараться переносить это, как ваши товарищи по несчастью, с помощью развлечения в оАно время и размышления в Аругое ${ }^{21}$.

Очевидно, Джонсон предпочел бы не доводить дело до развода.

Причин того, что юридически оформленный развод ассоциировался с причинением ущерба морали и репутации, было несколько. Во-первых, он должен был происходить по решению суда, что сопровождалось опросом свидетелей и выявлением интимных подробностей семейной жизни. Помимо лиц, непосредственно присутствовавших на слушании, доступ к этим сведениям мог получить самый широкий круг лиц. Возьмем в качестве примера дело о разводе леди Дианы Болингброк, которая вышла замуж за своего любовника Топхэма Боклерка после получения развода по акту парламента. Хорас Уолпол в переписке с другом в 1767 году закончил обсуждение последних событий следующим образом: 


\section{Царева А.П. «Свобода получить развод...»}

Это все наши новости общественного и частного характера, кроме развода лорда и леди Болингброк, который уже дело решенное...22.

Несмотря на то, что Уолпол заявляет о том, что ему не интересно данное событие, как и его адресату, автор письма хорошо осведомлен о положении дел и дальнейших шагах сторон: после развода леди Болингброк должна с согласия своей семьи выйти замуж за господина Боклерка, которого Уолпол именует «героем этой пьесы» 23 . Видимо, ему часто приходилось об этом слышать, так как в тоне Уолпола можно заметить усталость от постоянного повторения данной новости.

С течением времени охват аудитории становился все больше. Популярностью пользовались стенографические записи судебных заседаний, где во всех подробностях приводились свидетельства супружеской неверности, издавались целые сборники записей особо нашумевших дел 24 . Для более изысканной публики между 1769 и 1792 годах в свет вышли 24 выпуска Town and Country Magazine25, в которых смаковались подробности любовных похождений известных людей. Например, в 24-м выпуске была опубликована история измены молодой жены супругу, который был старше нее на 30 лет, с состоятельным любовником, который притворился слугой и был нанят в дом в качестве лакея. В статье не было напрямую названо семейство, о котором шла речь, действующие лица были указаны как «Мария», «сильный мужчина», и «пылкий любовник» 26 . Тем не менее, есть основания предполагать, что современники понимали, о ком шла речь.

22 Walpole. 1904: 148.

23 Walpole. 1904: 148.

24 Stone. 1995: 250.

25 Town and country magazine. 1769-1792.

26 Town and country magazine. 1792: 37, 38. 
Например, когда в 1793 году в Bon Ton Magazine была опубликована анонимная статья «Распутная жена, или Леди на соломе», в которой описывалась история романа леди Клары-Луизы Миддлтон с конюхом, начались разбирательства в суде, после чего статья была изъята из второго издания, а редакторы обещали опубликовать подробности свидетельских показаний после окончания судебного процесса ${ }^{27}$. Можно проследить истоки зарождения современной «желтой» журналистики в таких публикациях, попасть в которые, выставив на всеобщее обозрение свое «грязное белье», было крайне неприятно как самим супругам, так и их семьям.

Вторым фактором, способствовавшим негативному отношению, было то, что в Англии исследуемого периода причиной формального развода по акту парламента могла служить только супружеская неверность жены. При этом в других протестантских странах развод мог быть получен по одной их трех причин: неверность жены, исчезновение одного из супругов по собственной воле на несколько лет или чрезмерная жестокость, представляющая угрозу жизни ${ }^{28}$. Таким образом в Англии после развода муж всегда выступал в неприятной роли рогоносца, а жена приобретала дурную славу доступной женщины. При подобном отношении репутации супруги наносился более существенный урон. Не случайно в предложениях по возможной реформе бракоразводного законодательства 1771, 1779 и 1800 годов можно встретить пункт о запрете брака с любовником для жены ${ }^{29}$, поскольку именно в ее лице, по мысли законодателей, было необходимо наказать порок. Подобный подход брал начало еще в пе-

27 Stone. 1993: 223-224.

28 Stone. 1995: 301.

29 Andrew. 1997: 9, 11, 20. 


\section{Царева А.П. «Свобода получить развод...»}

риод Реформации и имел сторонников при обсуждении Акта о браке в 1857 году ${ }^{30}$.

Когда упомянутая выше Диана Болингброк, исполнявшая обязанности леди опочивальни при королеве Шарлотте, заявила во время бракоразводного процесса, что собирается прибыть для выполнения своих обязанностей ко двору, Хорас Уолпол посчитал, что «это всего лишь бравада» 31 . Неизвестно, смогла ли в итоге леди Диана осуществить задуманное, но она оставила свою должность, которую занимала с 1762 года, в том же году, когда получила развод (1768) ${ }^{32}$, что наталкивает на мысль о связи между этими двумя событиями.

При обсуждении с Сэмюэлом Джонсоном новости о разводе Болингброков, которые были их знакомыми, Джеймс Босуэлл приводил множество аргументов в защиту жены: жестокое отношение мужа, отсутствие привязанности в браке и превращение его в пустую формальность. Босуэлл с похвалой отзывался о Топхэме Боклерке, с которым леди Диана вступила в связь, и который также был их общим знакомым. Несмотря на все это, в глубине души он чувствовал, что неверность замужней женщины не может быть оправдана:

Пожалуй, плененный очарованием леди, о которой шла речь, я пытался таким образом извинить то, чему не могло быть оправАания... ${ }^{33}$.

Джонсон же высказался весьма лаконично:

Мой Аорогой сэр, никогАа не приучайте ваш разум смешивать Аобродетель и порок. Эта женщина - шлюха, вот и все ${ }^{34}$.

30 Woodhouse. 1959: 264, 265.

31 Walpole. 1904: 138.

32 Complete Peerage. 1912: 208.

33 Boswell. 2008: 392.

34 Boswell. 2008: 392. 
Как видно, несмотря на личное знакомство и замечательные качества леди Дианы, Босуэлл и Джонсон придерживались традиционного взгляда на роль супругов в разводе и принципиально осуждали ее поступок.

Можно было бы предположить, что после развода общение литераторов с леди Дианой прекратится, но этого не случилось. Одной из причин могли стать приятельские отношения с Топхэмом Боклерком, за которого она вышла замуж через два дня после принятия акта в парламенте 35 ; брак, впрочем, оказался несчастливым. Однако и о самой леди Диане в дальнейшем оба отзывались довольно тепло. Так, Сэмюэл Джонсон упоминал в письме Босуэллу о том, как она выхаживала больного мужа (Боклерка) с большим усердием, и называл ее «леди Ди» 36 . Босуэлл, бывший большим поклонником лексикографа, как-то даже выиграл у нее спор, задав Джонсону вопрос по поводу его привычки забирать с собой апельсиновые корки ${ }^{37}$. Вряд ли подобный спор мог быть возможен между людьми, не состоявшими в дружеских отношениях.

Другие знакомые также не отвернулись от леди Дианы. Когда ее второй муж умер в 1780 году, Эдмунд Бёрк заявил:

Я сам никогАа не наслаждался так видом чужого счастья, как видом этой женщины, когАа впервые увидел ее после смерти мужаз ${ }^{38}$.

Все собравшиеся, включая живописца Джошуа Рейнольдса, историка Эдварда Гиббона, епископа Сент-Эсэфа, сочувствовали вдове из-за жестокого обращения Топхэма Боклерка и выражали радость по поводу улучшения положения

35 Dictionary of National Biography. 1885: 35.

36 Boswell. 2008: 418.

37 Boswell. 2008: 439.

38 Burney. 2001: 183. 


\section{Царева А.П. «Свобода получить развод...»}

«леди Ди»: она получила в наследство дом и тысячу фунтов годового дохода. Даже писательница Фрэнсис (Фанни) Бёрни, известная своими высокими моральными стандартами, не высказалась негативно относительно леди Дианы. Она упоминает рассказанную Бёрком историю несчастливого брака четы Боклерков:

...страдания, которые он [муж - А.Ц.] причинил своей жене, его чрезвычайно плохое с ней обращение и необходимое облегчение, которое Аолжна принести смерть такого человека ${ }^{39}$.

Описание подробностей семейной жизни леди Дианы призвано было привлечь на ее сторону симпатии тех, кто подобно Бёрни не был знаком со всеми обстоятельствами ее второго замужества.

Статус разведенной женщины не помешал признанию художественных дарований леди Дианы. Хорас Уолпол использовал ее рисунки в качестве иллюстраций к своим произведениям, и даже отвел в своем поместье специальную комнату под ее работы; ее рисунки послужили основой также для иллюстраций к нескольким другим книгам, а в 1778 году она удостоилась чести написать портрет Джорджианы, герцогини Девонширской 40 . Умения леди Дианы ценились при дворе, несмотря на потерю места леди опочивальни. Как-то раз король в беседе с Фрэнсис Бёрни упомянул, что герцог Мальборо был дальтоником.

ОАнако я не нахожу, - добавил Его Величество, - что этот изъян присущ всей их семье; ибо леди Аи Боклерк [в Аевичестве Спенсер - А.Ц.] рисует весьма хорошо ${ }^{41}$.

39 Burney. 2001: 183.

40 Dictionary of National Biography. 1885: 36.

41 Burney. 2001: 220. 
Можно сделать вывод, что, несмотря на традиционно неодобрительное отношение к измене жены, которая являлась формальной причиной развода, ущерб, нанесенный репутации леди Дианы, отнюдь не оказался непоправимым. Она не подверглась остракизму, а продолжила вращаться в привычном кругу, и отношение к ней спустя некоторое время после бракоразводного процесса было вполне благожелательным.

Третьей причиной отношения к юридически оформленному разводу и получившим его лицам как к заслуживающим осуждения стало его ассоциирование с попранием моральных устоев в обществе в целом. Например, Эдвард Гиббон в «Истории заката и падения Римской империи» (177688) называл одной из причин упадка Рима его законы, дающие возможность получить развод по взаимному согласию сторон:

...этот свободный и совершенный эксперимент, который показывает, что свобода получить развод не приводит к счастью и добродетели ${ }^{42}$.

По мнению Гиббона, это приводило к утрате взаимного доверия, разжиганию споров и утрате целомудрия. Как видно из данного примера, историк полагал, что развод представлял угрозу для морального состояния общества, а в перспективе мог привести к нарушению порядка в обществе в целом.

После революционных событий во Франции отношение к разводу, узаконенному там в 1792 г., стало еще более настороженным. Джейн Уэст в 1799 г. опубликовала роман, в котором приписала «уничтожение тронов и алтарей не французскому оружию, но тем принципам [своевольное рас-

42 Gibbon. 1931: 413. 


\section{Царева А.П. «Свобода получить развод...»}

торжение (если не абсолютная недейственность) брачных уз и уничтожение родительской власти - А.Ц.], которые, устранив уверенность в домашнем очаге и принизив ценность личного пространства, проложили дорогу всеобщему заблуждению»43. Некоторые англичане, как видно из этих строк, стали прямо связывать возможность получения развода и революцию, полагая, что от подрыва семейных устоев недалеко и до подрыва устоев государственных.

Все чаще слышались голоса людей, усматривавших в нарастающем количестве разводов причины изменений в общественной морали. Так, лорд Честерфилд в 1765 году замечал в письме:

Собираются разводиться с женами бывший камергер Финч, ^орА Уорик и твой Аруг лорА Болингброк [речь иАет о разводе леАи Аианы с АорАом ФреАериком Болингброком - А.Ц.]. Ни оАин из этих трех разводов меня не удивляет, напротив, я поражаюсь тому, сколь многие продолжают еще жить вместе 44 .

Честерфилд дает понять, что возросшее количество разводов уже не шокирует и не возмущает. Вероятно, он все же несколько преувеличивает степень толерантности к разводам, и фраза звучит скорее как попытка продемонстрировать модное пренебрежение устоявшимися правилами приличия.

Если оценивать количество парламентских разводов, современному читателю оно может показаться совершенно незначительным. В промежуток между 1700 и 1857 годами, по подсчетам исследователей, парламент издал всего 322 акта о разводе 45 . С 1700 по 1749 год принималось от 2-х до 5ти актов за десятилетие (всего 14). Далее идет существенное

43 Цит. по: Rendall. 1985: 71.

44 Честерфим. 1978: 220.

45 Stone. 1995: 432-433. 
увеличение количества разводов, в диапазоне от 11 до 43 в десятилетие до 1800 года (всего 117 актов) ${ }^{46}$. Превышение показателей предыдущего периода более чем в 8 раз создавало у современников ощущение, что разводов стало пугающе много, хотя в абсолютных цифрах ситуация не выглядит столь плачевно. Например, в 1767 году в парламенте был принят один акт о разводе Джона Стотта, эсквайра, и его жены Джейн. В 1768 году, когда разводились лорд Болингброк и леди Диана, всего было принято три таких акта; оставшиеся два узаконили развод Чарлза Дэйли, эсквайра, с его женой Анной, и Томаса Брука, доктора физики, с его женой Харриет Нелфхоп ${ }^{47}$. Тем не менее, принятие трех актов в год по сравнению с двумя в десятилетие было существенным увеличением и способствовало росту опасений о том, что чрезмерная доступность разводов подрывает моральные устои общества.

Например, Хорас Уолпол примерно в это же время в переписке отмечает, что разводы стали происходить настолько часто, что начали восприниматься некоторыми почти как новая социальная норма:

Огастас Хервей, считая это хорошим тоном, собирается подать на развод с ЧаАли. Он спросил ^орда Болингброка, кто был его преАставителем в бракоразводном процессе, как если бы спросил о портном ${ }^{48}$.

Речь идет о непростой ситуации с браком Элизабет Чадли и морского офицера (впоследствии адмирала) Огастаса Хервея, к тому времени ставшего графом Бристольским. В

46 Тенденция к увеличению количества разводов сохранится в первой помовине XIX века, когАа число актов парламента за 1801-1857 гоА Аостигнет 191, хотя темпы роста замедлятся по отношению к преАыдущим 50ти годам. См.: Stone. 1995: 432.

47 Journals of the House of Commons. 1803: 76, 608, 666.

48 Walpole. 1904: 221. 


\section{Царева А.П. «Свобода получить развод...»}

1769 году суд признал за Элизабет статус незамужней, после чего она быстро вышла замуж за герцога Кингстонского ${ }^{49}$. Как можно видеть, отношение Хервея к бракоразводному процессу было более благожелательным, чем у Уолпола. Последнему казалось неприличным с легкостью поднимать эту тему в светских разговорах.

Влияние роста числа парламентских разводов на общественную мораль в реальности было гораздо скромнее, чем казалось современникам. Это было обусловлено их недоступностью абсолютному большинству населения в силу нескольких факторов: многоступенчатости процесса, длительности рассмотрения, высокой стоимости. Процедура развода в парламенте окончательно оформилась к началу XIX века. Предварительный этап состоял в том, что муж должен был сначала выиграть дело в церковном суде о разделении постели и крова, а также дело в суде общего права против любовника жены по обвинению в «преступном разговоре» (criminal conversation), либо представить объяснение, почему этого не произошло ${ }^{50}$. До 1798 и 1809 годов эти требования не были оформлены официально, но мужья все равно предпочитали заручиться решениями судов в свою пользу, прежде чем инициировать билль в парламенте.

Рассмотрение дела непосредственно в парламенте также могло занимать некоторое время. Примером быстрого бракоразводного процесса может послужить дело о разводе лорда Болингброка и леди Дианы. Первое обсуждение билля в Палате общин состоялось 29 февраля 1768 года, до этого его приняли в палате Лордов. Второе слушание состоялось 4 марта, третье - 7 марта, наконец, 10 марта состоялось под-

49 Dictionary of National Biography. 1887: 300.

50 Stone. 1995: 323, 324. 
писание акта о разводе королем Георгом III51. При этом предварительный этап с рассмотрением дела в церковном суде и суде общего права шел в октябре 1767 года, когда, по сообщению Х. Уолпола «она [леди Диана - А.Ц.] намерена признать все, что будет угодно моему лорду» ${ }^{52}$. Следует отметить, что дело о разводе лорда Болингброка проходило без протестов какой-либо из сторон.

В качестве примера бракоразводного процесса, который затягивался надолго, можно привести дело о разводе упомянутых выше супругов Миддлтон. В июне 1793 года Уильям Миддлтон подал иск в епископский суд Лондона для получения постановления о разделении постели и крова. Он привлек к даче показаний пятьдесят одного свидетеля обвинения, а его супруга Клара Луиза - пятьдесят девять свидетелей защиты, показания которых были получены и записаны в Лондоне, Йоркшире и Ирландии, а их копирование для представления в суд затянулось до осени 1794 года. В январе 1795 года Уильям Мидлтон также подал иск в суд Королевской скамьи о «преступном разговоре»его жены с любовником, которым оказался конюх Джон Роуз, запросив компенсацию в 10 тысяч фунтов. В феврале суд признал Роуза виновным и присудил ему выплатить Уильяму Миддлтону компенсацию в 500 фунтов, а также покрыть судебные издержки последнего на сумму 154 фунта. Параллельно продолжалось разбирательство в епископском суде, куда в январе 1795 года сторона мужа представила новые доказательства неверности жены. Клара-Луиза опротестовала их принятие в церковном апелляционном суде, которые принял заявление только в ноябре 1795 года, а вынес окончатель-

51 Journals of the House of Commons. 1803: 643, 656, 659, 666.

52 Walpole. 1904: 138. 


\section{Царева А.П. «Свобода получить развод...»}

ный вердикт (не в пользу Клары-Луизы) в мае 1796 года. Епископский суд Лондона принял новые доказательства к рассмотрению и решил дело в пользу мужа 53 . Судебные разбирательства с подачей встречных исков и вызовом множества свидетелей заняли около шести лет, при этом до развода в парламенте дело не дошло.

Полная стоимость бракоразводного процесса была очень высока. Помимо официальных судебных издержек следовало учитывать оплату расходов свидетелей, найма детективов, подготовки показаний, взятки и подкуп. По расчетам Л. Стоуна, супруги Миддлтон потратили на разбирательства не менее 1000 фунтов ${ }^{54}$. Формально предполагалось, что муж получает хотя бы частичную компенсацию по итогам рассмотрения дела о «преступном разговоре», когда любовника жены обязывали выплатить ему определенную сумму. Например, мужу леди Дианы виконту Болингброку было присуждено 500 фунтов, однако он ими не воспользовался55, что отражало общую тенденцию периода. Мужья лишь формально требовали денежной компенсации, на деле во многих случаях их куда больше интересовало само решение суда в их пользу для инициирования последующей процедуры развода в парламенте.

Подводя итог, можно выделить несколько причин негативного отношения к юридически оформленным разводам по актам парламента, которые, как казались современникам, наносили урон репутации и морали. Таковыми были: распространение информации о личной жизни среди широкого круга лиц; привязка разводов по акту парламента к неверно-

53 Stone. 1993: 223-225, 230, 234, 235.

54 Stone. 1993: 235.

55 Stone. 1993: 154. 
сти супруги; представление об опасности, связанной с легкостью получения развода, для состояния общества в целом. Между тем на примере развода леди Дианы Болингброк в 1768 г. можно видеть, что принципиальное осуждение ее поступка не привело к социальному остракизму; она продолжала вращаться в привычном кругу, ее имя произносилось без осуждения, а художественные работы высоко ценились. Во многом это было связано с тем, что она вступила в брак со своим любовником, а не осталась в статусе разведенной женщины. Отрицательное влияние разводов на мораль также преувеличивалось современниками, поскольку развод по акту парламента был доступен не всем в силу его стоимости, длительности процедуры и ее многоступенчатости. Рассмотрение частного случая леди Дианы позволяет сделать вывод о том, что последствия развода не всегда были столь негативными, как представлялось в теории. 


\section{Список источников и китературы}

\section{Источники}

Галифакс Д. 2001 - Галифакс Д. Новогодний подарок для леди, или Наставление дочери // Лабутина Т.Л. Воспитание и образование англичанки в XVII веке. СПб., 2001. С. 185 - 214.

Честерфилд Ф.Д. 1978 - Честерфилд Ф.Д. Письма к сыну. Максимы. Характеры. М., 1978.

Blackstone W. 1768 - Blackstone W. Commentaries on the laws of England: in 3 vols. Oxford, 1768. Book the first.

Boswell J. 2008 - Boswell J. The Life of Samuel Johnson. London, 2008.

Burney F. 2001 - BurneyF. Journals and Letters. London, 2001.

Dictionary of the English language. 1756 - A Dictionary of the English language: in which the words are deduced from their originals, explained in their different meanings, and authorized by the names of the writers in whose works they are found: in 2 vols. London, 1756. Vol. 1.

Gibbon E. 1931 - Gibbon E. The Decline and Fall of the Roman Empire: in 6 vols. New York, 1931.Vol 4.

Johnson S. 1952 - Johnson S. The Letters of Samuel Johnson: in 3 vols. Oxford, 1952. Vol. 1.

Journals of the House of Commons. 1803 - Journals of the House of Commons. Vol. 31, From November the 11th, 1766, In the Seventh Year of the Reign of King George the Third, to March the 10th, 1768, In the Eighth Year of the Reign of King George the Third. 1803.

Town and country magazine. 1769-1792 - The Town and country magazine, or, Universal repository of knowledge, instruction, and entertainment. London, 1769-1792. Hathi Trust Digital Library: https://catalog.hathitrust.org/Record/000493943

Walpole H. 1904 - Walpole H. The Letters of Horace Walpole, fourth earl of Orford, chronologically arranged and edited with notes and indices by Mrs. Paget Toynbee: in 16 vol. Oxford, 1904. Vol. VII: 1766-1771.

\section{МИТЕРАТУРА}

Andrew. 1997 - Andrew D. 'Adultery à-la-Mode': Privilege, the Law and Attitudes to Adultery 1770-1809 // History. Vol. 82, No. 265. 
1997. P. 5-23. Wiley: https://www.jstor.org/stable/24423572 (10.03.2021)

Complete Peerage of England. 1912 - The Complete Peerage of England, Scotland, Ireland, Great Britain and the United Kingdom Extant Extinct or Dormant by G.E.C. (George Edward Cokayne). In 13 vols. London, 1912. Vol. II.

Dictionary of National Biography. 1885 - Dictionary of National Biography: in 63 vols. // Edited by L. Stephen. N.Y., Londn, 1885.Vol. IV.

Dictionary of National Biography. 1887 - Dictionary of National Biography: in 63 vols. // Edited by L. Stephen. N.Y., London,1887.Vol. X.

James D. 2012 — James D. Parliamentary Divorce, 1700-1857 // Parliamentary History. Vol. 31, pt. 2. 2012. P. 169-189. Wiley: https://onlinelibrary.wiley.com/doi/pdf/10.1111/j.17500206.2012.00310.x (10.03.2021)

Rendall J. 1985 - Rendall J. The Origins of Modern Feminism: Women in Britain, France and the United States, 1780 - 1860. Basingstoke, London, 1985.

Staves S. 1990 - Staves S. Married Women's Separate Property in England, 1660 - 1833. Cambridge, Massachusetts, L., 1990.

Stone L. 1995 - Stone L. Road to Divorce, England 1530-1987. Oxford, New York, 1995.

Stone L. 1993 - Stone L. Broken Lives: separation and divorce in England, 1666-1857. New York, 1993.

Turner D. 2005 — Turner D. Popular Marriage and the Law: Tales of Bigamy at the Eighteenth-Century Old Bailey // The London Journal. Vol. 30, pt. 1. 2005. P. 6-21. Taylor \& Francis Online: https://doi.org/10.1179/ldn.2005.30.1.6

Woodhouse. 1959 - Woodhouse M. The Marriage and Divorce Bill of 1857 // The American Journal of Legal History. Vol. 3, No. 3. 1959. P. 260-275. Oxford University Press:

https://www.jstor.org/stable/843999 (10.03.2021) 